\title{
Strategies to Prevent Clostridium difficile Infections in Acute Care Hospitals: 2014 Update
}

\author{
Erik R. Dubberke, MD, MSPH; ${ }^{1}$ Philip Carling, MD; ${ }^{2}$ Ruth Carrico, PhD, RN; ${ }^{3}$ Curtis J. Donskey, MD; ${ }^{4}$ \\ Vivian G. Loo, MD, MSc; ${ }^{5}$ L. Clifford McDonald, MD; ${ }^{6}$ Lisa L. Maragakis, MD, MPH; ${ }^{7}$ \\ Thomas J. Sandora, MD, MPH; ${ }^{8}$ David J. Weber, MD, MPH; \\ Deborah S. Yokoe, MD, MPH; ${ }^{10}$ Dale N. Gerding, $\mathrm{MD}^{11}$
}

\section{PURPOSE}

Previously published guidelines are available that provide comprehensive recommendations for detecting and preventing healthcare-associated infections (HAIs). The intent of this document is to highlight practical recommendations in a concise format designed to assist acute care hospitals in implementing and prioritizing their Clostridium difficile infection (CDI) prevention efforts. This document updates "Strategies to Prevent Clostridium difficile Infections in Acute Care Hospitals,"1 published in 2008. This expert guidance document is sponsored by the Society for Healthcare Epidemiology of America (SHEA) and is the product of a collaborative effort led by SHEA, the Infectious Diseases Society of America (IDSA), the American Hospital Association (AHA), the Association for Professionals in Infection Control and Epidemiology (APIC), and The Joint Commission, with major contributions from representatives of a number of organizations and societies with content expertise. The list of endorsing and supporting organizations is presented in the introduction to the 2014 updates.

\section{SECTION 1: RATIONALE AND STATEMENTS OF CONCERN}

\section{Increasing rates of $\mathrm{CDI}$}

C. difficile now rivals methicillin-resistant Staphylococcus aureus (MRSA) as the most common organism to cause HAIs in the United States. ${ }^{3-5}$

A. In the United States, the proportion of hospital discharges in which a patient received the International
Classification of Diseases, Ninth Revision, Clinical Modification discharge diagnosis code for CDI more than doubled between 2000 and 2009. ${ }^{6}$ CDI rates may have leveled off, but they remain at historically high levels. These increases have been seen in pediatric and adult populations, but the elderly have been disproportionately affected. ${ }^{6} \mathrm{CDI}$ incidence has also increased in Canada and Europe..$^{7-9}$ Data on the changing epidemiology of CDI in pediatric patients are limited and are confounded by the prevalence of asymptomatic carriage of C. difficile among infants and very young children and by the presence of other pathogens among children with diarrhea and positive for $C$. difficile. ${ }^{10-12}$

B. CDI with onset outside the hospital may be more common than previously recognized, with more than $50 \%$ of CDIs having onset in the community. In addition, more than $75 \%$ of CDI cases have onset outside the acute care hospital. ${ }^{13} \mathrm{CDI}$ present on admission to the hospital may increase the risk of CDI for other hospitalized patients. ${ }^{14-16}$

C. There have been numerous reports of an increase in CDI severity. ${ }^{8,9,17-19}$ Most reports of increases in the incidence and severity of CDI have been associated with the BI/ NAP1/027 strain of $C$. difficile. ${ }^{8,9,18,19}$ Some studies have found that this strain produces more toxin $A$ and $B$ in vitro than most other strains of $C$. difficile, and it may produce more spores. ${ }^{20-22}$ It also produces a third toxin (binary toxin) and is highly resistant to fluoroquinolones. A strain commonly found in animals, polymerase chain reaction (PCR) ribotype 078 (which also has $t c d C$ gene

Affiliations: 1. Washington University School of Medicine, St. Louis, Missouri; 2. Boston University School of Medicine, Boston, Massachusetts; 3. Division of Infectious Diseases, University of Louisville School of Medicine, Louisville, Kentucky; 4. Case Western Reserve University, Louis Stokes Cleveland Veterans Affairs Medical Center, Cleveland, Ohio; 5. McGill University Health Centre, McGill University, Montreal, Quebec, Canada; 6. Division of Health care Quality Promotion, Centers for Disease Control and Prevention, Atlanta, Georgia; 7. Johns Hopkins University School of Medicine, Baltimore, Maryland; 8. Boston Children's Hospital, Harvard Medical School, Boston, Massachusetts; 9. School of Medicine, University of North Carolina, Chapel Hill, North Carolina; 10. Brigham and Women's Hospital and Harvard Medical School, Boston, Massachusetts; 11. Edward Hines Jr. Veterans Affairs Hospital, Hines, Illinois; and Loyola University Chicago Stritch School of Medicine, Chicago, Illinois.

Received February 12, 2014; accepted February 17, 2014; electronically published May 5, 2014.

Infect Control Hosp Epidemiol 2014;35(6):628-645

(C) 2014 by The Society for Healthcare Epidemiology of America. All rights reserved. 0899-823X/2014/3506-0002\$15.00. DOI: 10.1086/676023 
deletions and carries binary toxin), has been reported to have a higher 14-day mortality in the United Kingdom than BI/NAP1/027. ${ }^{23}$ In the United Kingdom, the BI/ NAP1/027 strain is no longer the predominant strain, and it occurs less frequently in continental Europe. ${ }^{7}$ In the United States, the prevalence of the BI/NAP1/027 strain averages approximately $25 \%-35 \%$ of CDI cases but ranges from $28 \%$ to $85 \%$ in adults. ${ }^{24-26}$

II. Outcomes associated with CDI

CDI is associated with increased length of hospital stay, costs, morbidity, and mortality in adult and pediatric patients. $^{27-30}$

A. CDI increases hospital length of stay by 2.8 to 5.5 days. ${ }^{28}$

B. Attributable costs of inpatient CDI in 2008 dollars have been estimated to be $\$ 3,006-\$ 15,397$ per episode. ${ }^{28}$ US hospital costs for CDI management have been estimated to be $\$ 1.0-4.9$ billion per year. ${ }^{28}$ Costs of CDI in the outpatient and non-acute care settings have not been assessed.

C. Patients with CDI were almost twice as likely to be discharged to a long-term care facility than propensity score-matched controls. ${ }^{27}$

D. The attributable mortality of CDI is estimated to be $5 \%-10 \%,^{8,9,23,27}$ leading to an estimated 14,000-20,000 deaths attributable to CDI in the United States each year. ${ }^{14,29}$

III. Changing risk factors and possible decrease in CDI treatment response rates

A. For the past 10 years, fluoroquinolones, previously infrequently associated with CDI, have been found to be one of the primary precipitating antimicrobials in recent studies. ${ }^{19,31}$

1. Virtually every antibiotic has been associated with CDI. Cephalosporins, ampicillin, and clindamycin remain important predisposing antibiotics. ${ }^{15}$

B. Gastric acid suppression has been recognized as a risk factor for CDI in some studies. ${ }^{15}$

1. Some studies suggest that the association between gastric acid suppression and CDI is related to other important risk factors, such as severity of illness and age. ${ }^{31}$

2. Gastric acid suppression may be an important risk factor for CDI outside healthcare facilities. ${ }^{32}$

C. Several studies suggest that rates of response to treatment of CDI with metronidazole are declining, including a randomized, prospective, blinded, severity-stratified study that demonstrated statistically superior rates of response to vancomycin for severe disease but not for mild disease compared with metronidazole. ${ }^{33-35}$

\section{SECTION 2: BACKGROUND-STRATEGIES}

\section{TO DETECT CDI}

\section{Surveillance definitions}

Definitions for CDI surveillance in the United States and Europe have been published. ${ }^{36,37}$
A. In the United Kingdom, all cases of CDI in patients over age 65 years have been required to report to the HAI surveillance system for National Health Service acute trusts since January 2004. Reporting for all CDI cases in those over age 2 years started in April 2007.

B. The Canadian Hospital Epidemiology Committee, a joint initiative of the Canadian Infectious Diseases Society and the Canadian Nosocomial Infection Surveillance Program, utilized a standard definition for CDI surveillance to track nosocomial CDI over a 4-month period in 1997 and after 2005 in healthcare facilities across Canada. ${ }^{9}$ This surveillance now occurs yearly.

C. The Centers for Medicare \& Medicaid Services (CMS) began requiring acute care hospitals participating in their Inpatient Prospective Payment System to report laboratory-identified CDI using the National Healthcare Safety Network (NHSN) in January 2013. Public reports by hospital of CDI rates will occur on the Hospital Compare website beginning in December 2013.

D. Data are lacking to determine the ideal surveillance definition for healthcare-associated CDI. However, more important than an ideal definition is the need for standardization in a CDI surveillance definition. The following information focuses on the definitions for CDI surveillance in the United States and Europe. ${ }^{36,37}$

1. A CDI case is defined as a case of clinically significant diarrhea or toxic megacolon without other known etiology that meets one or more of the following criteria: (1) either the stool sample yields a positive result for a laboratory assay for $C$. difficile toxin $\mathrm{A}$ and/or $\mathrm{B}$ or a toxin-producing $C$. difficile organism is detected in the stool sample by culture or other means, (2) pseudomembranous colitis is seen on endoscopic examination or surgery, and (3) pseudomembranous colitis is seen on histopathological examination.

a. The definition of clinically significant diarrhea has not been validated. Criteria used range from 3 or more than 3 diarrheal bowel movements within 24 hours or less to 6 diarrheal bowel movements in the previous 36 hours to at least 3 diarrheal bowel movements per day persisting for at least 2 days. Recent outbreaks of severe CDI indicate that it is not always possible to wait $24-48$ hours before determining whether a patient has clinically significant diarrhea; therefore, diarrhea plus abdominal cramping has also been used to satisfy criteria for clinically significant diarrhea. ${ }^{38,39}$ Conversely, it is normal for some patients to have 3 or more bowel movements per day. However, these are usually formed. Therefore, it is not possible to provide strict criteria for clinically significant diarrhea that can be applied to all patients. In general, clinically significant diarrhea in the context of CDI should consist of a sustained change in bowel movement consistency and/or frequency and/or abdominal 
та вLе 1. Clostridium Difficile Infection (CDI) Surveillance Definitions $\mathbf{s}^{22,23}$

\begin{tabular}{|c|c|}
\hline Case type & Definition \\
\hline Healthcare facility-onset, healthcare facility-associated CDI & $\begin{array}{l}\text { CDI symptom onset more than } 3 \text { days after admission to a healthcare } \\
\text { facility, with day of admission being day } 1\end{array}$ \\
\hline Community-onset, healthcare facility-associated CDI & $\begin{array}{l}\text { CDI symptom onset in the community or less than or equal to } 3 \text { days } \\
\text { from admission, provided symptom onset was less than } 4 \text { weeks after } \\
\text { the last discharge from a healthcare facility }\end{array}$ \\
\hline Community-associated CDI & $\begin{array}{l}\text { CDI symptom onset in the community or less than or equal to } 3 \text { days } \\
\text { after admission to a healthcare facility, provided that symptom onset } \\
\text { was more than } 12 \text { weeks after the last discharge from a healthcare } \\
\text { facility }\end{array}$ \\
\hline Indeterminate onset CDI & $\begin{array}{l}\text { CDI case patient who does not fit any of the above criteria for an expo- } \\
\text { sure setting (eg, onset in the community greater than } 4 \text { weeks but less } \\
\text { than } 12 \text { weeks after the last discharge from a healthcare facility) }\end{array}$ \\
\hline Unknown & Exposure setting cannot be determined because of lack of available data \\
\hline Recurrent CDI & $\begin{array}{l}\text { An episode of CDI that occurs less than or equal to } 8 \text { weeks after the } \\
\text { onset of a previous episode, provided that CDI symptoms from the } \\
\text { earlier episode resolved }\end{array}$ \\
\hline
\end{tabular}

NoTE. When utilizing laboratory-based reporting symptoms, date and time of stool specimen collection can be used as a surrogate for symptom onset. If data on the time a patient was admitted (in addition to date) and/or the time stool was collected for testing are not available, CDI can be considered healthcare facility onset if stool is positive for toxigenic $C$. difficile or toxin after the third calendar day from hospital admission, where the first day is the day of admission (ie, a patient admitted on Monday with stool first positive for $C$. difficile toxin on Thursday or later is considered to have healthcare facility-onset CDI).

cramping in a patient without other identified causes.

2. Several CDI definitions have been proposed, including community-associated CDI; community-onset CDI, healthcare facility-associated CDI; healthcareonset CDI; and recurrent CDI. Healthcare facilities should track at least healthcare-onset CDI (Table 1). ${ }^{40}$

3. Surveillance for CDI is limited by variation in patient selection for testing, lower sensitivity of toxin enzyme immunoassays (EIAs), lower specificity of nucleic acid amplification tests (NAATs), and prolonged turnaround time for the cell cytotoxicity cell assay as well as stool culture for toxigenic $C$. difficile. ${ }^{38,41,42} \mathrm{Lack}$ of culture-based methods for routine diagnosis also limits the availability of strains for molecular typing, although at least one PCR test for $C$. difficile will provide a presumptive identification of the BI/NAPl/ 027 strain.

II. Identifying patients with CDI

Positive results of diarrheal stool tests for toxigenic $C$. difficile or its toxins are the most common methods to identify patients with CDI. ${ }^{36,37,43}$

A. Results of positive diarrheal stool tests should be automatically sent to infection prevention and control (IPC) professionals and clinicians caring for the patient.

B. Test only patients with clinically significant diarrhea for C. difficile or its toxins. A positive test for toxigenic $C$. difficile and/or its toxins in a patient with clinically significant diarrhea is considered diagnostic for CDI. Testing patients without clinically significant diarrhea will decrease the positive predictive value of a positive test for CDI. ${ }^{38}$ Patients with formed stools should not be tested for $C$. difficile. ${ }^{44}$ Automatic, consecutive repeat testing for $C$. difficile will also increase the number false positive tests and has not been associated with better patient outcomes. ${ }^{45,46}$ However, if an institution permits C. difficile testing on nondiarrheal stools, patient record review is required to ensure that the patient has symptoms consistent with CDI.

1. Because of the high prevalence of asymptomatic carriage of toxigenic $C$. difficile among infants and very young children up to 2 years of age, testing for CDI is not advised in children under the age of 1 year and if done should be conducted only in those with diarrhea together with testing for alternative causes of diarrhea, especially rotavirus and norovirus. ${ }^{10,11}$ Detection of $C$. difficile toxin should not be assumed to be causative of diarrhea in infants and very young children unless there are no other plausible explanations.

C. A minority of cases are diagnosed by visualizing pseudomembranes at endoscopy and/or by histopathology without stool testing. ${ }^{43}$

III. Methods used for CDI surveillance

A. Conducting CDI surveillance to determine CDI rates provides a measure to determine the burden of CDI at a healthcare facility. These data are also utilized to assess efficacy of interventions to prevent CDI. When reported back to healthcare providers and hospital administrators, CDI rates can be applied as a tool to improve adherence to CDI preventive measures.

1. When conducting CDI surveillance, healthcare facilities can use traditional infection surveillance reporting 
or use laboratory-based reporting. Traditional reporting involves chart review to determine the date of symptom onset and whether the patient meets the surveillance definition for $\mathrm{CDI}$. Potential cases are typically identified by a laboratory test on stool positive for $C$. difficile and/or its toxins. Laboratory-based reporting also utilizes positive tests to identify cases, but chart review is not performed. Rather, it is assumed that all positive tests are patients with CDI, and the date of stool collection is used as a proxy for the date of symptom onset. Comparisons between the methods of surveillance have been performed, and the 2 methods typically have good concordance in correctly categorizing CDI cases into the proper surveillance definition. ${ }^{47,48}$ Although there are concerns that laboratory-based surveillance is less accurate and more likely to incorrectly classify community-onset CDI cases as hospital onset, this is not always the case. ${ }^{47}$ Even with the potential for some misclassification, the time savings of laboratory-based surveillance are often determined to outweigh the risks. ${ }^{47,48}$

B. Surveillance can be performed in specific wards or units and/or an entire healthcare facility level.

C. Laboratories performing $C$. difficile testing should report results to IPC professionals daily. The CDI rate can be expressed as the number of CDI case patients per 10,000 patient-days.

1. Calculation of this rate is as follows: (number of case patients/number of inpatient days per reporting period) $\times 10,000=$ rate per 10,000 inpatient-days.

2. To convert the rate per 10,000 patient-days to the rate per 1,000 patient-days, divide the rate by 10 (conversely, to convert a rate from 1,000 patient-days to 10,000 patient-days, multiply the rate by 10 ).

D. Because of a lack of published data on CDI surveillance utilizing similar case-finding methods and surveillance definitions, specific definitions for what constitutes an "outbreak" or "hyperendemic" rate cannot be provided at this time.

1. An outbreak can be defined as an increase in CDI in time and/or space believed to be greater than that expected by chance alone.

2. A hyperendemic rate can be defined as a persistently elevated CDI rate compared with past rates or compared with other similar healthcare facilities.

E. To adjust for factors outside a healthcare facility's control with regard to CDI rates, a risk stratification model has been proposed for use in NHSN and will be utilized for future public reporting of US hospital-onset CDI rates (http://www.cdc.gov/nhsn/PDFs/mrsa-cdi /RiskAdjustment-MRSA-CDI.pdf). The factors by which hospital rates are adjusted include the type of laboratory test in use, the prevalence of CDI on admission, bed size, and medical school affiliation. The risk-adjusted metric that will be publicly reported is the standardized infection ratio defined as the number of observed CDI cases divided by the expected number based on hospital risk stratification.

\section{SECTION 3: BACKGROUND-STRATEGIES}

\section{TO PREVENT CDI}

I. Summary of existing guidelines and recommendations

A. Published guidelines on the management of CDI are few, and only some address CDI prevention. ${ }^{44,49-51}$

1. Most data published on CDI prevention are from single-center before-after studies conducted in response to outbreaks or elevated CDI rates. Often several concomitant interventions are performed, making it difficult to determine the relative importance of one intervention relative to another. Before-after studies are also limited by time-related biases that are difficult to adjust for in the absence of a control group or properly conducted analyses, such as interrupted time-series analysis. ${ }^{52,53}$ However, several studies have utilized these techniques, demonstrating the importance of antimicrobial stewardship and its role in preventing CDI. ${ }^{54-57}$

B. C. difficile shares many common epidemiologic characteristics with other antimicrobial-resistant gram-positive organisms, such as MRSA and vancomycin-resistant enterococci (VRE). Both the skin and the environment of colonized patients becomes contaminated, and healthcare provider hands may become contaminated by touching the environment or the patient..$^{58-61}$ The major difference among these 3 organisms is that $C$. difficile forms spores, whereas the other 2 do not. The formation of spores poses unique challenges for hand hygiene and environmental disinfection practices, since $C$. difficile spores are resistant to the bactericidal effects of alcohol and the most commonly used hospital disinfectants. Although alcohol-based hand hygiene products are ineffective at removing or disinfecting $C$. difficile spores in controlled laboratory experiments, no clinical study has demonstrated an increase in CDI with the use of these products or a decrease in CDI with soap and water. ${ }^{62-68}$ Conversely, several of the studies did identify decreases in $\mathrm{MRSA}^{63-65,68}$ or $\mathrm{VRE}^{64}$ associated with the use of alcohol-based hand hygiene products.

A recent intensive care unit-based study found admission to a room of a patient with $\mathrm{CDI}$ to be a risk factor for CDI, but $90 \%$ of patients who developed CDI did not have this risk factor. ${ }^{69}$ Other studies that have examined sharing a room with a patient diagnosed with CDI or being admitted to a room after a patient with CDI was discharged from that room have not found these exposures to be risk factors for $\mathrm{CDI} .^{59,70-72}$ In addition, use of sporicidal methods to clean the environment outside of outbreak settings has not consistently demonstrated a reduction in CDI with these methods. ${ }^{73-75}$ These 
data indicate that although the environment can be an important source of $C$. difficile, indirect transmission by healthcare professionals may be the major route by which patients acquire $C$. difficile.

C. General strategies to prevent CDI per previously published guidelines ${ }^{44,49,51,76}$ include the following:

1. Methods to reduce the risk of CDI if the organism is encountered by the patient.

a. Antimicrobial usage restriction and stewardship.

2. Methods to prevent the patient from exposure to $C$. difficile (disinfection and barrier methods).

a. Avoid use of electronic thermometers; the handles become contaminated with $C$. difficile.

b. Use dedicated patient care items and equipment. If items must be shared, clean and disinfect the equipment between patients.

c. Use full-barrier precautions (gowns and gloves) for contact with CDI patients and for contact with their body substances and environment (contact precautions).

d. Place patients with CDI in private rooms if available. Give isolation preference to patients with fecal incontinence if room availability is limited.

e. Perform meticulous hand hygiene on the basis of Centers for Disease Control and Prevention (CDC) or World Health Organization (WHO) guidelines before and after entering the room (ie, to coincide with before patient contact and after removing gloves) of a patient with CDI with soap and water or an alcohol-based hand hygiene product (routine or endemic settings). Perform hand hygiene with soap and water preferentially instead of alcoholbased hand hygiene products after caring for a patient with CDI in outbreak or hyperendemic settings. Ensure that proper hand hygiene techniques are used when hand washing with soap and water is employed. ${ }^{77}$

f. Perform environmental decontamination of rooms of patients with CDI using sodium hypochlorite (household bleach) diluted 1:10 with water or an Environmental Protection Agency (EPA)-approved sporicidal product in an outbreak or hyperendemic setting.

g. Educate healthcare personnel (HCP) and hospital administration on clinical features, transmission, and epidemiology of CDI.

D. Other important principles to be aware of when caring for patients with CDI.

1. Perform testing for C. difficile only on unformed diarrheal stools from patients with clinically significant diarrhea (toxin testing of formed stool is strongly discouraged).

2. Do not place patients at high risk for CDI on prophylactic antimicrobial CDI therapy (eg, metronidazole or vancomycin).
3. Do not treat or decolonize asymptomatic $C$. difficile carriers. Antimicrobial therapy is not effective for decolonization.

4. Do not conduct repeat testing for $C$. difficile if a patient has had a positive stool for $C$. difficile unless symptoms resolved with treatment and then returned after treatment discontinuation (ie, do not perform test of cure in successfully treated CDI patients).

5. Most patients who are clinically cured with treatment will continue to have toxigenic $C$. difficile in their stool for multiple weeks. This is not an indication of treatment failure. Therefore, test of cure should not be conducted if a patient is being transferred to another healthcare facility. It is not appropriate for the accepting facility to refuse the patient until "clearance" has been documented with unnecessary stool testing.

II. Infrastructure requirements

A. Trained IPC personnel.

1. IPC personnel must have knowledge about risk factors and methods to prevent CDI. They must also be trained in how to determine when a case of CDI is healthcare associated and how to calculate CDI rates.

B. Method to identify CDI patients.

1. IPC personnel must be able to identify CDI patients as soon as possible after they are diagnosed. This is necessary to ensure that patients are placed under contact precautions in a timely fashion. These data can also be used to calculate CDI rates.

C. Ability to place patients with CDI under contact precautions.

1. Contact precautions require the ability to place patients in a private room (preferably) or to cohort patients with CDI as well as to place materials necessary for compliance with contact precautions (eg, gowns and gloves) in an easily accessible space outside the patient room.

2. Place a sign indicating that the patient is under contact precautions outside the patient's room. The sign should be in English and Spanish (or other language) if Spanish (or other language) is a commonly spoken language in the community or among healthcare providers.

3. If there are a limited number of single-bed rooms, patients with stool incontinence should preferentially be placed in private rooms.

4. If it is necessary to cohort patients, cohort patients colonized or infected with the same organism(s) (eg, do not cohort patients with CDI who are discordant on VRE or MRSA colonization status).

5. Dedicated equipment should be readily available for healthcare providers (eg, stethoscopes). If dedicated equipment is not available, responsibility for who will clean and disinfect equipment, when it will be cleaned and disinfected, and how it will be cleaned and disinfected must be clearly stated. 
TABLE 2. Grading of the Quality of Evidence

\begin{tabular}{|c|c|}
\hline Grade & Definition \\
\hline I. High & $\begin{array}{l}\text { Highly confident that the true effect lies close to that of the estimated size and direction of the } \\
\text { effect. Evidence is rated as high quality when there is a wide range of studies with no major } \\
\text { limitations, there is little variation between studies, and the summary estimate has a narrow } \\
\text { confidence interval. }\end{array}$ \\
\hline II. Moderate & $\begin{array}{l}\text { The true effect is likely to be close to the estimated size and direction of the effect, but there is } \\
\text { a possibility that it is substantially different. Evidence is rated as moderate quality when there } \\
\text { are only a few studies and some have limitations but not major flaws, there is some variation } \\
\text { between studies, or the confidence interval of the summary estimate is wide. }\end{array}$ \\
\hline III. Low & $\begin{array}{l}\text { The true effect may be substantially different from the estimated size and direction of the effect. } \\
\text { Evidence is rated as low quality when supporting studies have major flaws, there is important } \\
\text { variation between studies, the confidence interval of the summary estimate is very wide, or } \\
\text { there are no rigorous studies, only expert consensus. }\end{array}$ \\
\hline
\end{tabular}

NOTE. Based on Grades of Recommendation, Assessment, Development, and Evaluation (GRADE) ${ }^{122}$ and the Canadian Task Force on Preventive Health Care. ${ }^{123}$

6. Have systems in place to facilitate communication among IPC, admitting, nursing, and environmental service departments and develop contingency plans for limited bed availability conditions.

D. Provide educational materials for patients, family members, and HCP that include explanations of CDI, why contact precautions are necessary, and the importance of hand hygiene.

E. Provide adequate resources and training for environmental service personnel to ensure proper cleaning of rooms.

\section{SECTION 4：RECOMMENDED STRATEGIES FOR CDI PREVENTION}

Recommendations are categorized as either (1) basic practices that should be adopted by all acute care hospitals or (2) special approaches that can be considered for use in locations and/or populations within hospitals when HAIs are not controlled by use of basic practices. Basic practices include recommendations where the potential to impact HAI risk clearly outweighs the potential for undesirable effects. Special approaches include recommendations where the intervention is likely to reduce HAI risk but where there is concern about the risks for undesirable outcomes, where the quality of evidence is low, or where evidence supports the impact of the intervention in select settings (eg, during outbreaks) or for select patient populations. Hospitals can prioritize their efforts by initially focusing on implementing the prevention approaches listed as basic practices. If HAI surveillance or other risk assessments suggest that there are ongoing opportunities for improvement, hospitals should then consider adopting some or all of the prevention approaches listed as special approaches. These can be implemented in specific locations or patient populations or can be implemented hospital-wide, depending on outcome data, risk assessment, and/ or local requirements. Each infection prevention recommendation is given a quality-of-evidence grade (Table 2).

I. Basic practices for prevention and monitoring of CDI: recommended for all acute care hospitals

1. Encourage appropriate use of antimicrobials (quality of evidence: II).

a. Non-CDI treatment antimicrobials. Although the quality of evidence to recommend "encourage appropriate use of antimicrobials" to prevent CDI does not meet level 1 criteria (Table 2), the CDI panel felt that appropriate antimicrobial use as a CDI prevention measure is essential to any CDI prevention program. A major risk factor for hospitalized patients to acquire C. difficile is antecedent antimicrobial exposure. ${ }^{71,78}$ Encouraging appropriate antimicrobial use has been associated with reductions in CDI incidence in both endemic and outbreak settings. ${ }^{54-57}$ Appropriate antimicrobial use includes both avoiding antimicrobial exposures if the patient does not have a condition for which antimicrobials are indicated (eg, asymptomatic bacteriuria in a nonpregnant patient) and selecting antimicrobials associated with a lower risk of CDI when possible. ${ }^{79}$

b. CDI treatment antimicrobials. Assuring that patients with CDI are receiving appropriate severity-based treatment for their infection should be an additional goal for antimicrobial stewardship programs and may improve clinical outcome of CDI in these patients. In addition, monitoring for cessation of other antimicrobials when treating CDI is an important stewardship measure to reduce CDI recurrence. ${ }^{44,80,81}$

2. Use contact precautions for infected patients, singlepatient room preferred (quality of evidence: III for hand hygiene, II for gloves, III for gowns, III for single-patient room).

a. Place patients with CDI under contact precautions to 
help reduce patient-to-patient spread of the organism. $i$. Place patients in private rooms when available.

ii. Don gown and gloves upon entry to the patient's room.

(a) Gloves should be changed immediately if visibly soiled, after touching or handling surfaces or materials contaminated with feces, or after moving from a dirty to a clean intervention.

iii. Make dedicated patient care equipment readily available (eg, stethoscopes).

(a) Use dedicated equipment whenever possible.

(b) If equipment is shared between patients, do not bring the equipment into the patient room if possible (eg, glucometers).

(c) Clean the piece of equipment immediately after use. Identify who will clean and how to clean each piece of shared equipment.

iv. Remove gown and gloves prior to exiting the room.

v. Conduct CDC- or WHO-compliant hand hygiene upon exiting the patient's room.

vi. Cohorting CDI patients is acceptable when single private rooms are not available.

(a) Place patients with stool incontinence preferentially in private rooms.

(b) Do not cohort patients who are discordant with other epidemiologically important organisms (eg, VRE, MRSA).

(c) Remove gowns and gloves and perform hand hygiene when moving from one patient to the other.

b. Ensure that adequate supplies for contact precautions are readily available.

i. Management leaders are responsible to ensure that necessary barrier equipment supplies (eg, gowns, gloves), dedicated equipment, and hand hygiene products are readily available.

ii. Assign responsibility for monitoring the availability and restocking of supplies to specific HCP.

c. Criteria for discontinuing contact precautions are as follows:

$i$. The CDC currently recommends contact precautions for the duration of illness when caring for patients with CDI. ${ }^{82}$ Some experts recommend continuing contact precautions for at least 48 hours after diarrhea resolves.

(a) After resolution of symptoms, patients with CDI can continue to shed $C$. difficile in stool and contaminate the environment. ${ }^{83}$ In addition, these patients are at high risk for recurrent CDI after treatment is stopped. At this time, data do not exist to support extending isolation as a measure to decrease CDI incidence. Therefore, extending contact precautions until discharge for all patients with CDI remains a special approach. (b) Area of controversy. Asymptomatically colonized patients who have not had CDI can shed C. difficile spores, but the number of spores and degree of contamination is not as great as for patients with active CDI. ${ }^{72}$ There are currently no data to support detection or isolation of these asymptomatic patients.

3. Ensure cleaning and disinfection of equipment and the environment (quality of evidence: III for equipment, III for environment).

a. C. difficile spores contaminate the environment in which patients are housed and the equipment used to care for them. ${ }^{44}$ This includes the following:

i. Furnishings in the room, such as overbed tables, bedrails, furniture, sinks, floors, commodes, and toilets.

ii. Patient care equipment that directly touches patients, such as thermometers, stethoscopes, and blood pressure cuffs.

iii. Surfaces touched by healthcare workers and/or patients, such as doorknobs and intravenous infusion pumps.

iv. C. difficile may contaminate surfaces outside patient rooms, but the frequency of contamination and the number of spores are much lower than are typically present on surfaces inside CDI rooms. ${ }^{84,85}$

b. Contaminated surfaces and equipment are potential reservoirs for transmission of $C$. difficile.

i. Data are conflicting as to whether inactivation of spores is necessary to prevent $C$. difficile transmission, especially in an endemic setting.

ii. Facilities should consider using a 1:10 dilution of sodium hypochlorite (household bleach) or other product with the EPA-approved claim for $C$. difficile sporicidal activity (http://www.epa.gov/oppad001 /list_k_clostridium.pdf) to disinfect the environment in outbreak and hyperendemic settings in conjunction with other IPC measures (see "II. Special approaches for preventing CDI" below). The solution should have a contact time that meets the manufacturers' recommendations for $C$. difficile spores. See section 4.IV.7 for a discussion of touch-free disinfection technologies.

c. Develop and implement protocols for disinfection of equipment and the environment.

i. On a routine basis, assess adherence to protocols and the adequacy of cleaning and disinfection (http://www.cdc.gov/HAI/toolkits/Evaluating -Environmental-Cleaning.html).

ii. Assess the adequacy of cleaning and disinfection practices before changing to a new cleaning product (eg, bleach). If cleaning and disinfection practices are not adequate, address this before changing products (see "II. Special approaches for preventing CDI" below). 
iii. Ensure patient care equipment (eg, wall-mounted sphygmomanometers) and electronic equipment (eg, computers) that remain in the patient room are cleaned and disinfected.

$i v$. Because of high turnover of environmental service personnel, educate environmental service personnel on proper cleaning and disinfection technique frequently. Ensure that education is provided in the native language of the environmental service personnel.

d. Dedicate noncritical patient care items, such as blood pressure cuffs, stethoscopes, and thermometers, to a single patient with $C$. difficile.

$i$. When this is not possible, ensure adequate cleaning and disinfection of shared items between patient encounters. Ensure that manufacturers' recommendations for contact time of disinfectants are followed.

4. Implement a laboratory-based alert system to provide immediate notification to IPC and clinical personnel about newly diagnosed CDI patients (quality of evidence: III).

a. To place patients with CDI under contact precautions in a timely manner, it is important that an alert system be developed between the laboratory and both IPC and clinical personnel caring for the patient. This alert system should immediately notify IPC and clinical personnel when a patient is newly diagnosed with CDI.

b. There are a variety of methods by which this information can be transmitted, but some options include fax alerts, phone call and pager alerts, and automated secure electronic alerts.

$i$. The alert system should not rely on fax transmissions alone, since there may be delays from the time the transmission is received to the time it is seen by an appropriate healthcare provider.

c. Alert patient care areas of positive test results immediately so that these patients can be placed under contact precautions as soon as possible. Clear protocols regarding who is responsible for reporting this to the patient care location and who can isolate patients and remove patients from isolation should be available.

d. When a patient has CDI, communicate the CDI status when transferring the patient to another healthcare facility so appropriate precautions can be implemented at the accepting facility.

5. Conduct CDI surveillance and analyze and report CDI data (quality of evidence: III).

a. At a minimum, calculate healthcare-onset, healthcare-associated CDI rates at the unit/ward and/or organizational levels (Table 1 ). ${ }^{40}$

b. Provide CDI data and other CDI prevention process and outcome measures to key stakeholders, including senior leadership, physicians, nursing staff, and other clinicians.

c. Provide the process and outcome measures outlined in "Section 5: Performance Measures" below to appropriate hospital staff and administrators on a regular basis. The frequency with which these data are provided will depend on the hospital's existing reporting structure and the type of data collected. These data can be added to routine quality assessment and performance improvement reports.

6. Educate HCP, environmental service personnel, and hospital administration about CDI (quality of evidence: III).

a. Include risk factors, routes of transmission, local CDI epidemiology, patient outcomes and treatment, and prevention measures (including $\mathrm{CDC}$ and $\mathrm{WHO}$ recommendations on proper hand hygiene, contact precautions, and management of multidrug-resistant organisms).

7. Educate patients and their families about CDI as appropriate (quality of evidence: III).

a. Although often not considered part of a program to reduce transmission of multidrug-resistant organisms, proper education may help to alleviate patient and family fears regarding being placed in isolation. ${ }^{86}$ $i$. Include information about anticipated questions: general information about $\mathrm{CDI}$, colonization versus infection, the hospital's CDI prevention program, the components of and rationale for contact precautions, and the risk of transmission to family and visitors while in the hospital and after discharge. Helpful materials might include patient education sheets in appropriate language(s), the use of patient education channels, websites, or DVDs.

8. Measure compliance with $\mathrm{CDC}$ or WHO hand hygiene and contact precaution recommendations (quality of evidence: III).

a. Patient-to-patient transmission of $C$. difficile is thought to occur primarily through transient contamination of the hands of HCP with spores.

b. Glove use when caring for patients with CDI or touching surfaces in their rooms has been shown to be effective at preventing the transmission of $C$. difficile.

c. Hand hygiene practices in compliance with $\mathrm{CDC}$ or WHO guidelines may be important to $C$. difficile control and prevention. Evidence-based recommendations for implementation and assessment of hand hygiene programs in healthcare settings have been published. ${ }^{77}$

i. Area of controversy. There are concerns regarding reliance on alcohol-based hand hygiene products, since alcohol is not sporicidal. Several controlled studies have found alcohol-based hand hygiene products to be ineffective at removing/inactivating $C$. difficile 
spores from the hands of volunteers contaminated with a known number of spores compared with hand washing. ${ }^{87,88}$ Of note, one study did find a reduction in spores from the palmar surface of the hand with the alcohol-based hand hygiene product, ${ }^{87}$ and another recent publication found that most hand-wash products produced a less than $1 \log _{10}$ reduction in spores despite a 60 -second hand wash (30-second wash and 30-second rinse). ${ }^{89}$ When considering whether to promote hand washing over alcoholbased hand hygiene products after caring for a patient with $\mathrm{CDI}$, one should also consider that contamination of hands is less common when gloves are worn for the patient encounter; ${ }^{59}$ in addition, as previously stated several clinical studies have not found an increase in CDI with alcohol-based hand hygiene products, but several did find reductions in MRSA or VRE. ${ }^{62-68}$

II. Special approaches for preventing CDI

When CDI incidence remains higher than the institution's goal, a CDI risk assessment should be performed. Components of this risk assessment should include but not necessarily be limited to determining the location of new CDI cases within the affected area (ie, repeated cases in same room or cases scattered across multiple sites), the adequacy of contact precaution compliance, the adequacy of hand hygiene, and the adequacy of environment and equipment cleaning. Meetings with leadership and healthcare workers in the affected area should be conducted to identify potential opportunities to improve the CDI prevention plan. Contact the laboratory that performs the $C$. difficile assay(s) to determine whether there have been any changes in assay or assay performance. ${ }^{45}$

In addition to ensuring compliance with the basic recommendations, special approaches may be added to the CDI prevention program. However, there are several unresolved issues regarding CDI prevention. This is apparent when reviewing the rankings of each recommendation on the basis of the quality of the data to support it. As a result, implementation of the recommendations beyond the basic practices to prevent CDI should be individualized at each healthcare facility. One may consider a tiered approach in which recommendations are instituted individually or in groups; additional tiers are added if CDI rates do not improve, with implementation of basic practices as the first tier. Subsequent tiers should be prioritized on the basis of the CDI risk assessment.

A. Approaches to minimize C. difficile transmission by $\mathrm{HCP}$

1. Intensify the assessment of compliance with process measures (quality of evidence: III).

a. Contact precautions. Gowns and gloves should be worn by all HCP who enter the rooms of patients under contact precautions.

b. Hand hygiene. Hand hygiene should be performed at least on entry and exit from patient rooms.
When hand washing is performed, determine whether proper techniques are being used.

c. If hand hygiene compliance or techniques are not adequate, conduct interventions to improve hand hygiene compliance and techniques.

2. During outbreaks or in settings with hyperendemic CDI, perform hand hygiene with soap and water as the preferred method before exiting the room of a patient with CDI (quality of evidence: III).

a. Ensure proper hand hygiene technique when using soap and water.

b. Be aware that hand hygiene adherence may decrease when soap and water is the preferred method. ${ }^{77}$

$i$. Gloves are effective at preventing $C$. difficile contamination of hands. ${ }^{59}$

ii. Hand washing may remove less than $1 \log _{10}$ of spores, even with a 60 -second hand wash. ${ }^{89}$

iii. Alcohol-based hand hygiene products are superior to hand washing for non-spore-forming organisms (eg, MRSA).

iv. Reductions in CDI have not been observed with hand washing. ${ }^{62-68}$

3. Place patients with diarrhea under contact precautions while $C$. difficile testing is pending (quality of evidence: III).

a. To decrease transmission, it is essential to place symptomatic patients under contact precautions as soon as diarrhea symptoms are recognized, as this is the period of greatest $C$. difficile shedding and contamination. ${ }^{83}$

b. If $C$. difficile testing is negative, the patient has a low pretest probability of $\mathrm{CDI}$, and the patient is continent of stool, contact precautions can be discontinued.

i. Because of concerns about the low sensitivity of EIAs, clinical suspicion of CDI should outweigh negative test results in patients with a high pretest probability of having CDI, and the patient should remain under contact precautions.

ii. Because of its high negative predictive value, a negative NAAT result can be helpful for removing patients with diarrhea from isolation for suspected CDI.

4. Prolong the duration of contact precautions after the patient becomes asymptomatic until hospital discharge (quality of evidence: III).

B. Approaches to minimize $C$. difficile transmission from the environment

1. Assess the adequacy of room cleaning (quality of evidence: III).

a. If room cleaning and disinfection practices are deemed to be inadequate, focus on reviewing and improving cleaning and disinfection techniques.

b. Important issues to address include proper dilution of cleaning products, adequacy of cleaning and dis- 
infection technique, cleaning high-touch surfaces, frequency of changing rags/mop water, and moving from clean areas to dirty areas.

$i$. Create a unit-specific checklist based on cleaning protocols and perform observations to monitor cleaning practice. Use of fluorescent markers to monitor thoroughness of cleaning or adenosine triphosphate (ATP) bioluminescence to measure organic material on surfaces has been shown to be effective in improving cleaning and disinfection performance. ${ }^{90,91}$ However, these methods may not result in a reliable reduction in $C$. difficile spores from the environment. ${ }^{92}$

ii. Environmental cultures for $C$. difficile are difficult to perform and may require media not commercially available, and therefore they are not routinely recommended. ${ }^{93}$

c. Consider environmental decontamination with sodium hypochlorite or EPA-approved sporicidal agent if room cleaning and disinfection is deemed to be adequate but there is ongoing CDI transmission (see below).

2. Use an EPA-approved sporicidal disinfectant or diluted sodium hypochlorite for environmental cleaning and disinfection. Implement a system to coordinate with environmental services if it is determined that sodium hypochlorite is needed for environmental disinfection (quality of evidence: III).

a. Area of controversy. Data on the ability of diluted sodium hypochlorite or other sporicidal agents used for environmental decontamination to control CDI have not been consistent. However, a beneficial effect has been reported when bleach has been used in outbreak or hyperendemic settings, typically in conjunction with other enhanced CDI control measures. ${ }^{94.97}$

b. When diluted sodium hypochlorite is instituted for environmental decontamination, it is necessary to coordinate activities with environmental services.

i. Clinical, IPC, and environmental service staff will need to determine the location, type, and frequency of diluted sodium hypochlorite use. For instance:

(a) All rooms, only rooms of patients with CDI, outside patient rooms, and so on.

(b) Daily cleaning or terminal cleaning only when the patient is discharged or transferred? Daily disinfection of high-touch surfaces in CDI and MRSA rooms has been shown to reduce acquisition of the pathogens on investigators' hands after contact with surfaces and to decrease contamination of the hands of the providers caring for the patients. ${ }^{98}$

c. When diluted sodium hypochlorite is used, it is important to address the following issues: i. Avoid toxicity to patients and staff and damage to equipment and the environment from bleach use. Sodium hypochlorite can be corrosive and irritating to patients, housekeepers, and other HCP.

ii. Prior to application of diluted sodium hypochlorite, surfaces must be cleaned to remove organic matter.

d. When a sporicidal method will be used only in rooms with CDI patients, a system will need to be created to identify these patients to environmental service staff.

e. See section 4.IV.7 for a discussion of touch-free disinfection technologies.

C. Approaches to reduce the risk of CDI if $C$. difficile is acquired

1. Initiate an antimicrobial stewardship program (quality of evidence: II).

a. Assess appropriateness of antimicrobial prescribing practices.

$i$. There are 2 primary approaches to antimicrobial stewardship when done specifically to prevent $\mathrm{CDI}$, restricting high-risk antimicrobials and improving overall antimicrobial prescribing practices. Of note, these approaches are not mutually exclusive.

ii. Restriction of specific high-risk antimicrobials (eg, clindamycin, cephalosporins, and fluoroquinolones) has been effective in outbreak settings and should be based on local CDI epidemiology. ${ }^{99-101}$ Monitoring should be conducted to ensure that other antimicrobials are not used inappropriately as a replacement for the restricted antimicrobial. If an acceptable alternative first-line antimicrobial to treat the primary non-CDI infection is not available, the high-risk antimicrobial should be used.

iii. Improving antimicrobial prescribing practices has been effective in outbreak and nonoutbreak setting $\mathrm{s}^{54,55}$ Research has demonstrated that a large proportion of patients who receive antimicrobials do not have a bacterial infection. ${ }^{54,55}$ Minimizing these unnecessary antimicrobials reduces the number of patients at risk for CDI. Therefore, minimizing unnecessary antimicrobials exposures should also reduce the number of patients who develop CDI and contribute to C. difficile transmission.

III. Approaches that should not be considered a routine part of CDI prevention

1. Patients without signs or symptoms of CDI should not be tested for $C$. difficile (quality of evidence: II).

a. C. difficile assays have been studied in patients with symptoms of CDI and a high pretest probability of having $C$. difficile infection. A positive $C$. difficile assay 
from a patient without symptoms is falsely positive for CDI. ${ }^{38}$

i. Only stool culture for $C$. difficile has been confirmed to identify patients with asymptomatic $C$. difficile colonization. The sensitivity, specificity, negative predictive value, and positive predictive value of other assays are unknown in asymptomatic patients.

b. Obtaining stool specimens requires nursing time to collect the specimen and laboratory technician time to perform the test and report results.

c. A positive toxin result in an asymptomatic patient may result in the initiation of unnecessary treatment for CDI, which may increase the patient's risk of developing CDI in the future. ${ }^{102}$

d. Do not place patients with asymptomatic $C$. difficile colonization under contact precautions.

$i$. Area of controversy. Routine screening for asymptomatic carriage of $C$. difficile is not recommended. However, patients with recent CDI are a subset of asymptomatic carriers for whom prolongation of contact precautions may be considered as a special approach if basic measures are unsuccessful. The rationale is that these patients are at high risk for recurrence and continued shedding is common for several weeks after successful treatment. How to manage patients found to be colonized with $C$. difficile but without prior or present CDI is unclear (eg, a patient positive by PCR but without clinically significant diarrhea). The benefits of placing these patients under contact precautions (decreased transmission of $C$. difficile to other patients) must be balanced with the risks (in the absence of universal screening, it will be unlikely to impact CDI incidence) and potential for adverse events due to contact precautions. ${ }^{103-106}$

e. Do not attempt to decolonize asymptomatic patients since this has not been effective and may increase the patient's risk of developing CDI in the future. ${ }^{102}$

2. C. difficile testing should not be repeated at the end of successful therapy in a patient recently treated for CDI (quality of evidence: III).

a. A positive test may result in unnecessary prolongation of contact precautions and CDI treatment.

$i$. In some settings, contact precautions may be extended until hospital discharge after symptom resolution. However, there are insufficient data to recommend extending the duration of contact precautions on the basis of whether $C$. difficile or its toxins can be detected in the patient's stool.

b. A positive test at the end of therapy does not predict who will develop a recurrence or relapse. ${ }^{107}$

c. Repeat $C$. difficile testing does not provide any useful clinical information but does require nursing time to collect the specimen and laboratory technician time to perform the test and report results.

d. It is not appropriate for healthcare facilities to request repeat $C$. difficile testing in a patient prior to transfer in the absence of a clinical syndrome consistent with an undiagnosed and/or untreated case of CDI.

3. Do not routinely place patients who are on antimicrobials for other indications on CDI treatment to prevent CDI (quality of evidence: III).

a. Unnecessary treatment for CDI may increase the patient's risk of developing CDI in the future. ${ }^{102}$

IV. Unresolved issues

1. Use of gowns and gloves by family members and other visitors.

a. The utility of requiring family members and other visitors to wear gowns and gloves to prevent $C$. difficile transmission is unknown. ${ }^{108}$ The risk that family members and other visitors will transmit $C$. difficile between patients is likely to be related to the degree of contact the visitor has with the patient and the patient's environment, whether the visitor performs hand hygiene, and the degree of interaction the visitor has with other patients. At a minimum, family members and other visitors should be instructed to perform hand hygiene whenever entering or leaving the patient's room. If family members do not wear gowns and gloves, they should be educated and instructed to use proper hand washing technique prior to leaving the patient's room.

2. Standing orders or nurse-driven protocols to test patients with diarrhea for $C$. difficile.

a. Nurses frequently identify patients with diarrhea before the treating physician does.

b. If nurses are permitted to send a stool specimen for C. difficile testing prior to obtaining a physician order, they should be educated on proper patient selection for $C$. difficile testing (ie, clinically significant diarrhea in a patient without other reasons for clinically significant diarrhea).

3. Admission-based alert systems that notify IPC and clinical personnel about readmitted or transferred patients with a history of CDI.

a. This information can be integrated into a computerized database used during admission and registration or a separate electronic or paper-based database. $i$. If an alert system is implemented, patients with a history of CDI should be placed under contact precautions if they are readmitted only if they have symptoms consistent with $\mathrm{CDI}$ on admission. Asymptomatic patients with a history of CDI do not require contact precautions.

ii. The duration that the alert should remain active is unknown. Nearly all cases of recurrent CDI occur within 90 days of the last episode. In light of this, it is reasonable to eliminate the alert after 90 days from the last episode of CDI. However, healthcare facilities may not be aware of recurrent episodes of CDI that are diagnosed and managed in outpatient settings, so an arbitrary cutoff based on the last 
known episode of CDI may inadvertently remove patients with ongoing recurrent $\mathrm{CDI}$.

4. Ongoing assessment of CDI knowledge and intensified CDI education among HCP.

a. Reeducate staff if prior CDI training occurred more than 12 months earlier or if overall knowledge is deemed to be inadequate.

$i$. Include environmental service personnel in educational efforts.

5. Restricting the use of gastric acid suppressants.

a. Whether gastric acid suppressants are a contributing cause of CDI or a marker for patients at risk for CDI is not clear. There are no data suggesting restricting gastric acid suppressants is associated with reductions in CDI.

6. Prescribing probiotics as primary prophylaxis.

a. Recent meta-analyses indicated that probiotics may be effective as primary prophylaxis against CDI. ${ }^{109,110} \mathrm{~A}$ concern with these meta-analyses is that the studies with the greatest weight had extremely high incidences of CDI in the placebo groups ( $7 \%, 24 \%$, and $40 \%)$. The incidence of CDI in high-risk patients without contraindications to probiotics is typically less than or equal to $3 \% .^{111,112}$ The high incidence of CDI in the placebo group has the potential to bias their findings to favor the probiotics. For example, a recent large randomized controlled trial of probiotic versus placebo with a more typical CDI incidence in the placebo arm (1.2\%) failed to demonstrate a reduction in CDI with the use of a probiotic. ${ }^{113}$ In addition, many hospitalized patients have relative contraindications to probiotics (eg, central venous catheter, immunocompromised) that place them at increased risk of infection due to the probiotic strain(s). ${ }^{114}$

7. No-touch disinfection technologies.

a. Several no-touch disinfection products are commercially available. In general, these products use ultraviolet light or hydrogen peroxide vapor to disinfect the environment. ${ }^{73,92,115}$ These devices kill $C$. difficile spores, and several studies have found them to be effective at reducing cultivatable $C$. difficile from patient rooms. ${ }^{73,92,115}$ Although sporicidal activity can be achieved without requiring a person to wipe down a surface, the use of these devices does not preclude the need to manually clean soiled surfaces. ${ }^{73,92}$ Data are currently too limited to draw any conclusions as to whether or when these devices should be a component of a CDI prevention program. In addition, excellent results can be achieved with manual cleaning with a sporicidal disinfectant. ${ }^{92}$

\section{SECTION 5: PERFORMANCE MEASURES}

\section{Internal reporting}

These performance measures are intended to support internal hospital quality improvement efforts and do not necessarily address external reporting needs. The process and outcome measures suggested here are derived from published guidelines, other relevant literature, and the opinions of the authors. Report process and outcome measures to senior hospital leadership, nursing leadership, and clinicians who care for patients at risk for CDI.

\section{A. Process measures}

1. Compliance with hand hygiene guidelines.

a. Preferred measure for hand hygiene compliance.

i. Numerator: number of observed proper hand hygiene episodes performed by HCP.

ii. Denominator: total number of observed opportunities for hand hygiene.

iii. Multiply by 100 so that the measure is expressed as a percentage.

b. If hand hygiene with soap and water is the preferred method of hand hygiene when caring for patients with CDI, also assess proper hand washing techniques.

i. Numerator: number of proper hand washing episodes with proper technique.

ii. Denominator: total number of hand washing episodes observed.

iii. Multiply by 100 so that the measure is expressed as a percentage.

2. Compliance with contact precautions.

a. Preferred measure of contact precautions compliance.

i. Numerator: number of observed patient care episodes in which contact precautions are appropriately implemented.

ii. Denominator: number of observed patient care episodes in which contact precautions are indicated.

iii. Multiply by 100 so that the measure is expressed as a percentage.

3. Compliance with environmental cleaning and disinfection.

a. One specific measure of compliance for use in all hospitals cannot be recommended. However, many hospitals use checklists, environmental rounds, fluorescent markers, and/or ATP bioluminescence to assess the cleaning and disinfection process and the cleanliness of equipment and the environment (see above).

B. Outcome measures

Perform ongoing measurement of the incidence density of CDI to permit longitudinal assessment of the processes of care.

1. CDI rates should be calculated according to the recently published recommendations and as described above.

a. See Table 1 for case definitions.

i. Numerator: number of CDI cases in the population being monitored (specific cases included in the numerator depends on the defi- 
TABLE 3. Fundamental Elements of Accountability for Healthcare-Associated Infection Prevention

Senior management is responsible for ensuring that the healthcare system supports an infection prevention and control (IPC) program that effectively prevents healthcare-associated infections (HAIs) and the transmission of epidemiologically important pathogens

Senior management is accountable for ensuring that an adequate number of trained personnel are assigned to the IPC program and adequate staffing of other departments that play a key role in HAI prevention (eg, environmental services)

Senior management is accountable for ensuring that healthcare personnel, including licensed and nonlicensed personnel, are adequately trained and competent to perform their job responsibilities

Direct healthcare providers (such as physicians, nurses, aides, and therapists) and ancillary personnel (such as environmental service and equipment processing personnel) are responsible for ensuring that appropriate IPC practices are used at all times (including hand hygiene, standard and isolation precautions, and cleaning and disinfection of equipment and the environment)

Senior and unit leaders are responsible for holding personnel accountable for their actions

IPC leadership is responsible for ensuring that an active program to identify HAIs is implemented, that HAI data are analyzed and regularly provided to those who can use the information to improve the quality of care (eg, unit staff, clinicians, and hospital administrators), and that evidence-based practices are incorporated into the program

Senior and unit leaders are accountable for ensuring that appropriate training and educational programs to prevent HAIs are developed and provided to personnel, patients, and families

Personnel from the IPC program, the laboratory, and information technology departments are responsible for ensuring that systems are in place to support the surveillance program

nition used; see Table 1).

ii. Denominator: total number of patient-days in the population being monitored.

iii. Multiply by 10,000 so that the measure is expressed as the number of cases per 10,000 patient-days (note: to convert the rate per 10,000 patient-days to 1,000 patient-days, divide the rate by 10; conversely, to convert a rate from 1,000 patient-days to 10,000 patient-days, multiply the rate by 10 ).

II. External reporting

There are many challenges in providing useful information to consumers and other stakeholders while preventing unintended adverse consequences of public reporting of HAIs. ${ }^{116}$ Recommendations for public reporting of HAIs have been provided by the Hospital Infection Control Practices Advisory Committee, the Healthcare-Associated Infection Working Group of the Joint Public Policy Committee, and the National Quality Forum. ${ }^{116,117}$

A. State and federal requirements

1. The CMS began requiring acute care hospitals participating in their Inpatient Prospective Payment System to report laboratory-identified CDI using NHSN in January 2013.

2. For information on local requirements, check with your state or local health department.

B. External quality initiatives

1. Hospitals that participate in external quality initiatives must collect and report the data if required by the initiative.

\section{SECTION 6: EXAMPLES OF}

\section{IMPLEMENTATION STRATEGIES}

Accountability is an essential principle for preventing HAIs. It provides the necessary translational link between science and implementation. Without clear accountability, scientifically based implementation strategies will be used in an inconsistent and fragmented way, decreasing their effectiveness in preventing HAIs. Accountability begins with the chief executive officer and other senior leaders who provide the imperative for HAI prevention, thereby making HAI prevention an organizational priority. Senior leadership is accountable for providing adequate resources needed for effective implementation of an HAI prevention program. These resources include necessary personnel (clinical and nonclinical), education, and equipment (Table 3).

Successful implementation strategies used as part of collaboratives and working groups include engage, educate, execute, and evaluate. ${ }^{96,118}$ Strategies that have been shown to be effective in addressing CDI within healthcare settings are provided in this section.

\section{Engage}

A. Multidisciplinary involvement

1. To address the complexities involved in the implementation of prevention strategies for CDI, broadscope involvement of hospital personnel should be an integral part of the process. This approach serves to engage key stakeholders in the prevention and care stages of the infection.

2. Identification and engagement of a multidisciplinary team should be an initial step in implementation of a CDI prevention plan. The team should involve representation from senior leadership, unit-level leadership, individual healthcare providers, laboratory personnel, pharmacy, environmental services, materials management, and information technology. Goals should be established and accountability embedded in the process. Recent successes have been demonstrated through development of a multidisciplinary and specific $C$. difficile infection control plan based on a risk assessment. ${ }^{96}$ 
II. Educate

A. Educate personnel

1. Provide education to HCP, environmental services personnel, executive level leadership, and others, including at least the following: risk factors for CDI, transmission, local epidemiology, patient outcomes, treatment, hand hygiene, contact precautions, management of multidrug-resistant organisms, and individual job responsibilities. ${ }^{77,108}$ Provide information in the native language of the personnel whenever possible.

2. Identify and implement methods for education and training of personnel that allow immersive experiences that enhance critical thinking and decisionmaking skills, including simulation experiences. ${ }^{119}$

B. Educate patients and their families about CDI

1. Provide education to patients and their families regarding CDI (http://www.cdc.gov/hai/organisms /cdiff/Cdiff-patient.html). Education should include at least the following: general information about CDI (including risk for recurrent CDI), colonization versus infection, elements in the facility CDI prevention program, components of and rationale for contact precautions, and risks of transmission to family and visitors while in the hospital and after discharge.

2. Provide education and assist patients with performance of hand hygiene as an approach to preventing acquisition of pathogens. ${ }^{120}$

III. Execute

A. Initiate a CDI prevention program

1. Perform a CDI risk assessment as a basis for a comprehensive and multidisciplinary intervention. ${ }^{96}$

a. Define local CDI epidemiology.

i. Identify high-risk wards and wards with a high incidence of hospital-onset CDI.

ii. Determine whether hospital-onset CDI cases are sporadic or occur repeatedly in the same $\operatorname{room}(\mathrm{s}) .{ }^{121}$

(a) If sporadic, suggests patient-to-patient transmission from healthcare workers or traveling fomites.

(b) If repeated in same room, suggests transmission from contaminated environment.

2. Pilot-test the intervention in one patient care location to assess efficacy.

a. Initiate the prevention program where there is a high concentration of patients at risk for CDI, such as an intensive care unit or an oncology ward.

b. Start in one patient care location.

i. Identify opportunities to improve the system for identifying patients with CDI.

ii. Identify opportunities to improve the process for placing patients with CDI in contact precaution rooms and to minimize problems for family members, visitors, and HCP. iii. Identify opportunities to optimize hand hygiene, contact precautions, and environmental cleaning compliance.

c. Obtain support of the hospital administration and local physician and nursing leadership prior to starting the program.

d. Standardize care processes and practices using bundles, checklists, protocols, and guidelines. ${ }^{94,96}$ Empower staff to report process defects to appropriate personnel as a means of facilitating rapid intervention and identification of barriers. Assign accountability for adherence to specific departments or functions. ${ }^{96}$

e. Create redundancy in the system by incorporating use of visual cues as reminders and assistance to recall. For example, have indicators that the patient is under contact precautions in the electronic medical records, paper medical records, and signage on the door to the patient room.

3. Replicate the CDI IPC program in other patient care areas when it is determined that the systems developed are effective.

IV. Evaluate

\section{A. Performance monitoring}

1. Use process measures (did you successfully implement your intervention?) and outcome measures (how well did the intervention achieve the desired outcome?) to determine whether the intervention is effective.

2. Measure both process and outcomes on a regular basis.

B. Feedback to staff

1. Provide monitoring data in various formats so it can be posted and broadly disseminated. Incorporate monitoring data into unit-based and departmentbased measurements so trending over time can be evaluated..$^{94,96}$

2. Provide feedback to all levels of personnel regarding process and outcomes. Provide feedback via committee reports as well as facility newsletters.

3. Individualize feedback so respective patient care areas and individual departments can use data for comparative and goal-setting purposes.

4. Use feedback to determine specific interventions or improvements for targeted focus. ${ }^{118}$

\section{ACKNOWLEDGMENTS}

Disclaimer. L.C.M.-The findings and conclusions in this report are those of the authors and do not necessarily represent the official position of the Centers for Disease Control and Prevention.

Potential conflicts of interest. E.R.D. reports serving as an advisor/consultant for Sanofi Pasteur, Merck, and Pfizer and receiving research grants/ contracts from Sanofi Pasteur, ViroPharma, Optimer, Merck, and Rebiotix. P.C. reports serving as an advisor/consultant for Steris and holding a patent/ copyright/license with Ecolab. R.C. reports serving on the speakers' bureau for Sanofi Pasteur, MedImmune, Abbott Diabetes Care, and 3M; performing technical writing for Ketchum; and receiving research grants/contracts from 
Sanofi Pasteur. C.J.D. reports serving as an advisor/consultant for Steris, GOJO Industries, and 3M; receiving honoraria from Ecolab; and receiving research grants/contracts from Merck, ViroPharma, Steris, and Pfizer. V.G.L. reports serving as an advisor/consultant for Optimer Pharmaceuticals. D.J.W. reports serving as an advisor/consultant for Johnson \& Johnson and Clorox. D.N.G. reports serving as an advisor/consultant for Merck, Cubist, Novartis, Cangene, Actelion, ViroPharma, Rebiotix, and Sanofi Pasteur; receiving honoraria from Robert Michael; holding a patent/license (no royalties) with ViroPharma; and receiving research grant/contracts from GOJO Industries. L.C.M., L.L.M., T.J.S., and D.S.Y. report no conflicts of interest.

Address correspondence to Erik R. Dubberke, MD, MSPH, Washington University School of Medicine, 660 South Euclid Avenue, Box 8051, St. Louis, MO 63110 (edubberk@dom.wustl.edu).

\section{REFERENCES}

1. Dubberke ER, Gerding DN, Classen D, et al. Strategies to prevent Clostridium difficile infections in acute care hospitals. Infect Control Hosp Epidemiol 2008;29(suppl 1):S81-\$92.

2. Yokoe DS, Anderson DJ, Berenholtz SM, et al. Introduction to "A Compendium of Strategies to Prevent Healthcare-Associated Infections in Acute Care Hospitals: 2014 Updates." Infect Control Hosp Epidemiol 2014;35(5):455-459.

3. McDonald LC, Owings M, Jernigan DB. Clostridium difficile infection in patients discharged from US short-stay hospitals, 1996-2003. Emerg Infect Dis 2006;12(3):409-415.

4. Miller BA, Chen LF, Sexton DJ, Anderson DJ. Comparison of the burdens of hospital-onset, healthcare facility-associated Clostridium difficile infection and of healthcare-associated infection due to methicillin-resistant Staphylococcus aureus in community hospitals. Infect Control Hosp Epidemiol 2011; 32(4):387-390.

5. Zilberberg MD, Shorr AF, Kollef MH. Growth and geographic variation in hospitalizations with resistant infections, United States, 2000-2005. Emerg Infect Dis 2008;14(11):1756-1758.

6. Lucado J, Gould C, Elixhauser A. Clostridium difficile Infection (CDI) Hospital Stays, 2009. HCUP Statistical Brief 124. Rockville, MD: Agency for Healthcare Research and Quality, 2012. http://www.hcup-us.ahrq.gov/reports/statbriefs/sb124.pdf.

7. Bauer MP, Notermans DW, van Benthem BH, et al. Clostridium difficile infection in Europe: a hospital-based survey. Lancet 2011;377(9759):63-73.

8. Loo VG, Poirier L, Miller MA, et al. A predominantly clonal multi-institutional outbreak of Clostridium difficile-associated diarrhea with high morbidity and mortality. NEngl JMed 2005; 353(23):2442-2449.

9. Miller M, Gravel D, Mulvey M, et al. Health care-associated Clostridium difficile infection in Canada: patient age and infecting strain type are highly predictive of severe outcome and mortality. Clin Infect Dis 2010;50(2):194-201.

10. Denno DM, Shaikh N, Stapp JR, et al. Diarrhea etiology in a pediatric emergency department: a case control study. Clin Infect Dis 2012;55(7):897-904.

11. Feghaly RE, Stauber JL, Tarr PI, Haslam DB. Viral co-infections are common and are associated with higher bacterial burden in children with Clostridium difficile infection. J Pediatr Gastroenterol Nutr 2013;57(6):813-816.

12. Rousseau C, Poilane I, De Pontual L, Maherault AC, Le Monnier A, Collignon A. Clostridium difficile carriage in healthy infants in the community: a potential reservoir for pathogenic strains. Clin Infect Dis 2012;55(9):1209-1215.
13. Vital signs: preventing Clostridium difficile infections. MMWR Morb Mortal Wkly Rep 2012;61:157-162.

14. Campbell RJ, Giljahn L, Machesky K, et al. Clostridium difficile infection in Ohio hospitals and nursing homes during 2006. Infect Control Hosp Epidemiol 2009;30(6):526-533.

15. Dubberke ER, Reske KA, Yan Y, Olsen MA, McDonald LC, Fraser VJ. Clostridium difficile-associated disease in a setting of endemicity: identification of novel risk factors. Clin Infect Dis 2007;45(12):1543-1549.

16. Dubberke ER, Butler AM, Yokoe DS, et al. Multicenter study of Clostridium difficile infection rates from 2000 to 2006. Infect Control Hosp Epidemiol 2010;31(10):1030-1037.

17. Kim J, Shaklee JF, Smathers S, et al. Risk factors and outcomes associated with severe Clostridium difficile infection in children. Pediatr Infect Dis J 2012;31(2):134-138.

18. Kuijper EJ, Barbut F, Brazier JS, et al. Update of Clostridium difficile infection due to PCR ribotype 027 in Europe, 2008. Euro Surveill 2008;13(31).

19. McDonald LC, Killgore GE, Thompson A, et al. An epidemic, toxin gene-variant strain of Clostridium difficile. $N$ Engl J Med 2005;353(23):2433-2441.

20. Burns DA, Heeg D, Cartman ST, Minton NP. Reconsidering the sporulation characteristics of hypervirulent Clostridium difficile BI/NAP1/027. PLOS ONE 2011;6(9):e24894.

21. Merrigan M, Venugopal A, Mallozzi M, et al. Human hypervirulent Clostridium difficile strains exhibit increased sporulation as well as robust toxin production. $J$ Bacteriol 2010; 192(19):4904-4911.

22. Warny M, Pepin J, Fang A, et al. Toxin production by an emerging strain of Clostridium difficile associated with outbreaks of severe disease in North America and Europe. Lancet 2005;366(9491):1079-1084.

23. Walker AS, Eyre DW, Wyllie DH, et al. Relationship between bacterial strain type, host biomarkers, and mortality in Clostridium difficile infection. Clin Infect Dis 2013;56(11):1589-1600.

24. Black SR, Weaver $\mathrm{KN}$, Jones $\mathrm{RC}$, et al. Clostridium difficile outbreak strain BI is highly endemic in Chicago area hospitals. Infect Control Hosp Epidemiol 2011;32(9):897-902.

25. Cheknis AK, Sambol SP, Davidson DM, et al. Distribution of Clostridium difficile strains from a North American, European and Australian trial of treatment for $C$. difficile infections: 2005-2007. Anaerobe 2009;15(6):230-233.

26. Lessa FC. Incidence and insights into $C$. difficile infection epidemiology. ID Week. October 18, 2012.

27. Dubberke ER, Butler AM, Reske KA, et al. Attributable outcomes of endemic Clostridium difficile-associated disease in nonsurgical patients. Emerg Infect Dis 2008;14(7):1031-1038.

28. Dubberke ER, Olsen MA. Burden of Clostridium difficile on the healthcare system. Clin Infect Dis 2012;55(suppl 2):S88\$92.

29. Hall AJ, Curns AT, McDonald LC, Parashar UD, Lopman BA. The roles of Clostridium difficile and norovirus among gastroenteritis-associated deaths in the United States, 1999-2007. Clin Infect Dis 2012;55(2):216-223.

30. Sammons JS, Localio R, Xiao R, Coffin SE, Zaoutis T. Clostridium difficile infection is associated with increased risk of death and prolonged hospitalization in children. Clin Infect Dis 2013;57(1):1-8.

31. Pepin J, Saheb N, Coulombe MA, et al. Emergence of fluoroquinolones as the predominant risk factor for Clostridium 
difficile-associated diarrhea: a cohort study during an epidemic in Quebec. Clin Infect Dis 2005;41(9):1254-1260.

32. Dial S, Delaney JA, Barkun AN, Suissa S. Use of gastric acidsuppressive agents and the risk of community-acquired Clostridium difficile-associated disease. JAMA 2005;294(23):29892995.

33. Belmares J, Gerding DN, Parada JP, Miskevics S, Weaver F, Johnson S. Outcome of metronidazole therapy for Clostridium difficile disease and correlation with a scoring system. I Infect 2007;55(6):495-501.

34. Musher DM, Aslam S, Logan N, et al. Relatively poor outcome after treatment of Clostridium difficile colitis with metronidazole. Clin Infect Dis 2005;40(11):1586-1590.

35. Zar FA, Bakkanagari SR, Moorthi KM, Davis MB. A comparison of vancomycin and metronidazole for the treatment of Clostridium difficile-associated diarrhea, stratified by disease severity. Clin Infect Dis 2007;45(3):302-307.

36. Kuijper EJ, Coignard B, Tull P. Emergence of Clostridium difficile-associated disease in North America and Europe. Clin Microbiol Infect 2006;12(suppl 6):2-18.

37. McDonald LC, Coignard B, Dubberke E, Song X, Horan T, Kutty PK. Recommendations for surveillance of Clostridium difficile-associated disease. Infect Control Hosp Epidemiol 2007; 28(2):140-145.

38. Dubberke ER, Han Z, Bobo L, et al. Impact of clinical symptoms on interpretation of diagnostic assays for Clostridium difficile infections. J Clin Microbiol 2011;49(8):2887-2893.

39. Pepin J, Valiquette L, Cossette B. Mortality attributable to nosocomial Clostridium difficile-associated disease during an epidemic caused by a hypervirulent strain in Quebec. CMAJ2005; 173(9):1037-1042.

40. Dubberke ER, Butler AM, Hota B, et al. Multicenter study of the impact of community-onset Clostridium difficile infection on surveillance for $C$. difficile infection. Infect Control Hosp Epidemiol 2009;30(6):518-525.

41. Longtin Y, Trottier S, Brochu G, et al. Impact of the type of diagnostic assay on Clostridium difficile infection and complication rates in a mandatory reporting program. Clin Infect Dis 2013;56(1):67-73.

42. Planche TD, Davies KA, Coen PG, et al. Differences in outcome according to Clostridium difficile testing method: a prospective multicentre diagnostic validation study of $C$ difficile infection. Lancet Infect Dis 2013;13(11):936-945.

43. Dubberke ER, Reske KA, McDonald LC, Fraser VJ. ICD-9 codes and surveillance for Clostridium difficile-associated disease. Emerg Infect Dis 2006;12(10):1576-1579.

44. Cohen SH, Gerding DN, Johnson S, et al. Clinical practice guidelines for Clostridium difficile infection in adults: 2010 update by the Society for Healthcare Epidemiology of America (SHEA) and the Infectious Diseases Society of America (IDSA). Infect Control Hosp Epidemiol 2010;31(5):431-455.

45. Litvin M, Reske KA, Mayfield J, et al. Identification of a pseudooutbreak of Clostridium difficile infection (CDI) and the effect of repeated testing, sensitivity, and specificity on perceived prevalence of CDI. Infect Control Hosp Epidemiol 2009;30(12): 1166-1171.

46. Polage CR, Chin DL, Leslie JL, Tang J, Cohen SH, Solnick JV. Outcomes in patients tested for Clostridium difficile toxins. Diagn Microbiol Infect Dis 2012;74(4):369-373.

47. Dubberke ER Jr, Nyazee HA, Yokoe DS, et al. Implementing automated surveillance for tracking Clostridium difficile infec- tion at multiple healthcare facilities. Infect Control Hosp Epidemiol 2012;33(3):305-308.

48. Gase KA, Haley VB, Xiong K, Van Antwerpen C, Stricof RL. Comparison of 2 Clostridium difficile surveillance methods: $\mathrm{Na}$ tional Healthcare Safety Network's laboratory-identified event reporting module versus clinical infection surveillance. Infect Control Hosp Epidemiol 2013;34(3):284-290.

49. Bauer MP, Kuijper EJ, van Dissel JT. European Society of Clinical Microbiology and Infectious Diseases (ESCMID): treatment guidance document for Clostridium difficile infection (CDI). Clin Microbiol Infect 2009;15(12):1067-1079.

50. Simor AE, Bradley SF, Strausbaugh LJ, Crossley K, Nicolle LE. Clostridium difficile in long-term-care facilities for the elderly. Infect Control Hosp Epidemiol 2002;23(11):696-703.

51. Surawicz CM, Brandt LJ, Binion DG, et al. Guidelines for diagnosis, treatment, and prevention of Clostridium difficile infections. Am J Gastroenterol 2013;108(4):478-498.

52. Harris AD, Bradham DD, Baumgarten M, Zuckerman IH, Fink JC, Perencevich EN. The use and interpretation of quasiexperimental studies in infectious diseases. Clin Infect Dis 2004; 38(11):1586-1591.

53. Stone SP, Cooper BS, Kibbler CC, et al. The ORION statement: guidelines for transparent reporting of outbreak reports and intervention studies of nosocomial infection. Lancet Infect Dis 2007;7(4):282-288.

54. Fowler S, Webber A, Cooper BS, et al. Successful use of feedback to improve antibiotic prescribing and reduce Clostridium difficile infection: a controlled interrupted time series. J Antimicrob Chemother 2007;59(5):990-995.

55. Valiquette L, Cossette B, Garant MP, Diab H, Pepin J. Impact of a reduction in the use of high-risk antibiotics on the course of an epidemic of Clostridium difficile-associated disease caused by the hypervirulent NAP1/027 strain. Clin Infect Dis 2007; 45(suppl 2):S112-S121.

56. Aldeyab MA, Kearney MP, Scott MG, et al. An evaluation of the impact of antibiotic stewardship on reducing the use of high-risk antibiotics and its effect on the incidence of Clostridium difficile infection in hospital settings. J Antimicrob Chemother 2012;67(12):2988-2996.

57. Talpaert MJ, Gopal RG, Cooper BS, Wade P. Impact of guidelines and enhanced antibiotic stewardship on reducing broadspectrum antibiotic usage and its effect on incidence of Clostridium difficile infection. J Antimicrob Chemother 2011;66(9): 2168-2174.

58. Guerrero DM, Nerandzic MM, Jury LA, Jinno S, Chang S, Donskey CJ. Acquisition of spores on gloved hands after contact with the skin of patients with Clostridium difficile infection and with environmental surfaces in their rooms. Am J Infect Control 2012;40(6):556-558.

59. McFarland LV, Mulligan ME, Kwok RY, Stamm WE. Nosocomial acquisition of Clostridium difficile infection. $N$ Engl $J$ Med 1989;320(4):204-210.

60. Stiefel U, Cadnum JL, Eckstein BC, Guerrero DM, Tima MA, Donskey CJ. Contamination of hands with methicillin-resistant Staphylococcus aureus after contact with environmental surfaces and after contact with the skin of colonized patients. Infect Control Hosp Epidemiol 2011;32(2):185-187.

61. Hayden MK, Blom DW, Lyle EA, Moore CG, Weinstein RA. Risk of hand or glove contamination after contact with patients colonized with vancomycin-resistant Enterococcus or the col- 
onized patients' environment. Infect Control Hosp Epidemiol 2008;29(2):149-154.

62. Boyce JM, Ligi C, Kohan C, Dumigan D, Havill NL. Lack of association between the increased incidence of Clostridium difficile-associated disease and the increasing use of alcohol-based hand rubs. Infect Control Hosp Epidemiol 2006;27(5):479-483.

63. Gopal RG, Jeanes A, Osman M, Aylott C, Green J. Marketing hand hygiene in hospitals-a case study. I Hosp Infect 2002; $50(1): 42-47$

64. Gordin FM, Schultz ME, Huber RA, Gill JA. Reduction in nosocomial transmission of drug-resistant bacteria after introduction of an alcohol-based handrub. Infect Control Hosp Epidemiol 2005;26(7):650-653.

65. Kaier K, Hagist C, Frank U, Conrad A, Meyer E. Two timeseries analyses of the impact of antibiotic consumption and alcohol-based hand disinfection on the incidences of nosocomial methicillin-resistant Staphylococcus aureus infection and Clostridium difficile infection. Infect Control Hosp Epidemiol 2009;30(4):346-353.

66. Knight N, Strait T, Anthony N, et al. Clostridium difficile colitis: a retrospective study of incidence and severity before and after institution of an alcohol-based hand rub policy. Am J Infect Control 2010;38(7):523-528.

67. Rupp ME, Fitzgerald T, Puumala S, et al. Prospective, controlled, cross-over trial of alcohol-based hand gel in critical care units. Infect Control Hosp Epidemiol 2008;29(1):8-15.

68. Vernaz N, Sax H, Pittet D, Bonnabry P, Schrenzel J, Harbarth S. Temporal effects of antibiotic use and hand rub consumption on the incidence of MRSA and Clostridium difficile. I Antimicrob Chemother 2008;62(3):601-607.

69. Shaughnessy MK, Micielli RL, Depestel DD, et al. Evaluation of hospital room assignment and acquisition of Clostridium difficile infection. Infect Control Hosp Epidemiol 2011;32(3): 201-206.

70. Chang VT, Nelson $\mathrm{K}$. The role of physical proximity in nosocomial diarrhea. Clin Infect Dis 2000;31(3):717-722.

71. Clabots CR, Johnson S, Olson MM, Peterson LR, Gerding DN. Acquisition of Clostridium difficile by hospitalized patients: evidence for colonized new admissions as a source of infection. J Infect Dis 1992;166(3):561-567.

72. Samore MH, Venkataraman L, DeGirolami PC, Arbeit RD, Karchmer AW. Clinical and molecular epidemiology of sporadic and clustered cases of nosocomial Clostridium difficile diarrhea. Am J Med 1996;100(1):32-40.

73. Boyce JM, Havill NL, Otter JA, et al. Impact of hydrogen peroxide vapor room decontamination on Clostridium difficile environmental contamination and transmission in a healthcare setting. Infect Control Hosp Epidemiol 2008;29(8):723-729.

74. Mayfield JL, Leet T, Miller J, Mundy LM. Environmental control to reduce transmission of Clostridium difficile. Clin Infect Dis 2000;31(4):995-1000.

75. Wilcox MH, Fawley WN, Wigglesworth N, Parnell P, Verity P, Freeman J. Comparison of the effect of detergent versus hypochlorite cleaning on environmental contamination and incidence of Clostridium difficile infection. I Hosp Infect 2003; 54(2):109-114.

76. Simor AE. Diagnosis, management, and prevention of Clostridium difficile infection in long-term care facilities: a review. J Am Geriatr Soc 2010;58(8):1556-1564.

77. Boyce JM, Pittet D; Society for Healthcare Epidemiology of
America, Association for Professionals in Infection Control, and Infectious Diseases Society of America. Guideline for hand hygiene in health-care settings: recommendations of the Healthcare Infection Control Practices Advisory Committee and the HICPAC/SHEA/APIC/IDSA Hand Hygiene Task Force. MMWR Recomm Rep 2002;51(RR-16):1-45.

78. Loo VG, Bourgault AM, Poirier $L$, et al. Host and pathogen factors for Clostridium difficile infection and colonization. $N$ Engl J Med 2011;365(18):1693-1703.

79. Doernberg SB, Winston LG, Deck DH, Chambers HF. Does doxycycline protect against development of Clostridium difficile infection? Clin Infect Dis 2012;55(5):615-620.

80. Le F, Arora V, Shah DN, Salazar M, Palmer HR, Garey KW. A real-world evaluation of oral vancomycin for severe Clostridium difficile infection: implications for antibiotic stewardship programs. Pharmacotherapy 2012;32(2):129-134.

81. Harpe SE, Inocencio TJ, Pakyz AL, Oinonen MJ, Polk RE. Characterization of continued antibacterial therapy after diagnosis of hospital-onset Clostridium difficile infection: implications for antimicrobial stewardship. Pharmacotherapy 2012; 32(8):744-754.

82. Frequently asked questions about Clostridium difficile for healthcare providers. Centers for Disease Control and Prevention website. 2005. http://www.cdc.gov/HAI/organisms/cdiff /Cdiff_faqs_HCP.html.

83. Sethi AK, Al Nassir WN, Nerandzic MM, Bobulsky GS, Donskey CJ. Persistence of skin contamination and environmental shedding of Clostridium difficile during and after treatment of C. difficile infection. Infect Control Hosp Epidemiol 2010;31(1): 21-27.

84. Dubberke ER, Reske KA, Noble-Wang J, et al. Prevalence of Clostridium difficile environmental contamination and strain variability in multiple health care facilities. Am J Infect Control 2007;35(5):315-318.

85. Dumford DM III, Nerandzic MM, Eckstein BC, Donskey CJ. What is on that keyboard? detecting hidden environmental reservoirs of Clostridium difficile during an outbreak associated with North American pulsed-field gel electrophoresis type 1 strains. Am J Infect Control 2009;37(1):15-19.

86. Lewis AM, Gammon J, Hosein I. The pros and cons of isolation and containment. J Hosp Infect 1999;43(1):19-23.

87. Jabbar U, Leischner J, Kasper D, et al. Effectiveness of alcoholbased hand rubs for removal of Clostridium difficile spores from hands. Infect Control Hosp Epidemiol 2010;31(6):565-570.

88. Oughton MT, Loo VG, Dendukuri N, Fenn S, Libman MD. Hand hygiene with soap and water is superior to alcohol rub and antiseptic wipes for removal of Clostridium difficile. Infect Control Hosp Epidemiol 2009;30(10):939-944.

89. Edmonds SL, Zapka C, Kasper D, et al. Effectiveness of hand hygiene for removal of Clostridium difficile spores from hands. Infect Control Hosp Epidemiol 2013;34(3):302-305.

90. Boyce JM, Havill NL, Dumigan DG, Golebiewski M, Balogun $\mathrm{O}$, Rizvani R. Monitoring the effectiveness of hospital cleaning practices by use of an adenosine triphosphate bioluminescence assay. Infect Control Hosp Epidemiol 2009;30(7):678-684.

91. Carling PC, Parry MF, Von Beheren SM. Identifying opportunities to enhance environmental cleaning in 23 acute care hospitals. Infect Control Hosp Epidemiol 2008;29(1):1-7.

92. Sitzlar B, Deshpande A, Fertelli D, Kundrapu S, Sethi AK, Donskey CJ. An environmental disinfection odyssey: evaluation 
of sequential interventions to improve disinfection of Clostridium difficile isolation rooms. Infect Control Hosp Epidemiol 2013;34(5):459-465.

93. Wilcox MH, Fawley WN, Parnell P. Value of lysozyme agar incorporation and alkaline thioglycollate exposure for the environmental recovery of Clostridium difficile. J Hosp Infect 2000; 44(1):65-69.

94. Abbett SK, Yokoe DS, Lipsitz SR, et al. Proposed checklist of hospital interventions to decrease the incidence of healthcareassociated Clostridium difficile infection. Infect Control Hosp Epidemiol 2009;30(11):1062-1069.

95. McMullen KM, Zack J, Coopersmith CM, Kollef M, Dubberke E, Warren DK. Use of hypochlorite solution to decrease rates of Clostridium difficile-associated diarrhea. Infect Control Hosp Epiderniol 2007;28(2):205-207.

96. Mermel LA, Jefferson J, Blanchard K, et al. Reducing Clostridium difficile incidence, colectomies, and mortality in the hospital setting: a successful multidisciplinary approach. Jt Comm J Qual Patient Saf 2013;39(7):298-305.

97. Orenstein R, Aronhalt KC, McManus JE Jr, Fedraw LA. A targeted strategy to wipe out Clostridium difficile. Infect Control Hosp Epidemiol 2011;32(11):1137-1139.

98. Kundrapu S, Sunkesula V, Jury LA, Sitzlar BM, Donskey CJ. Daily disinfection of high-touch surfaces in isolation rooms to reduce contamination of healthcare workers' hands. Infect Control Hosp Epidemiol 2012;33(10):1039-1042.

99. Kallen AJ, Thompson A, Ristaino P, et al. Complete restriction of fluoroquinolone use to control an outbreak of Clostridium difficile infection at a community hospital. Infect Control Hosp Epidemiol 2009;30(3):264-272.

100. McNulty C, Logan M, Donald IP, et al. Successful control of Clostridium difficile infection in an elderly care unit through use of a restrictive antibiotic policy. $J$ Antimicrob Chemother 1997;40(5):707-711.

101. Pear SM, Williamson TH, Bettin KM, Gerding DN, Galgiani JN. Decrease in nosocomial Clostridium difficile-associated diarrhea by restricting clindamycin use. Ann Intern Med 1994; 120(4):272-277.

102. Johnson S, Homann SR, Bettin KM, et al. Treatment of asymptomatic Clostridium difficile carriers (fecal excretors) with vancomycin or metronidazole: a randomized, placebo-controlled trial. Ann Intern Med 1992;117(4):297-302.

103. Kirkland KB, Weinstein JM. Adverse effects of contact isolation. Lancet 1999;354(9185):1177-1178.

104. Morgan DJ, Diekema DJ, Sepkowitz K, Perencevich EN. Adverse outcomes associated with contact precautions: a review of the literature. Am I Infect Control 2009;37(2):85-93.

105. Saint S, Higgins LA, Nallamothu BK, Chenoweth C. Do physicians examine patients in contact isolation less frequently? a brief report. Am J Infect Control 2003;31(6):354-356.

106. Stelfox HT, Bates DW, Redelmeier DA. Safety of patients isolated for infection control. JAMA 2003;290(14):1899-1905.

107. McFarland LV, Elmer GW, Surawicz CM. Breaking the cycle: treatment strategies for 163 cases of recurrent Clostridium difficile disease. Am J Gastroenterol 2002;97(7):1769-1775.

108. Siegel JD, Rhinehart E, Jackson M, Chiarello L. 2007 Guideline for isolation precautions: preventing transmission of infectious agents in health care settings. Am J Infect Control 2007;35(10 suppl 2):S65-S164.
109. Goldenberg JZ, Ma SS, Saxton JD, et al. Probiotics for the prevention of Clostridium difficile-associated diarrhea in adults and children. Cochrane Database Syst Rev 2013;5:CD006095.

110. Johnston BC, Ma SS, Goldenberg JZ, et al. Probiotics for the prevention of Clostridium difficile-associated diarrhea: a systematic review and meta-analysis. Ann Intern Med 2012; 157(12):878-888.

111. Dubberke ER, Yan Y, Reske KA, et al. Development and validation of a Clostridium difficile infection risk prediction model. Infect Control Hosp Epidemiol 2011;32(4):360-366.

112. Gupta S, Miller M, Mehta V, et al. A large prospective North American epidemiologic study of hospital-associated Clostridium difficile colonization and infection. International Clostridium difficile Symposium; Bled, Slovenia; abstract O20. September 22, 2012.

113. Allen SI, Wareham K, Wang D, et al. Lactobacilli and bifidobacteria in the prevention of antibiotic-associated diarrhoea and Clostridium difficile diarrhoea in older inpatients (PLACIDE): a randomised, double-blind, placebo-controlled, multicentre trial. Lancet 2013;382(9900):1249-1257.

114. Munoz P, Bouza E, Cuenca-Estrella M, et al. Saccharomyces cerevisiae fungemia: an emerging infectious disease. Clin Infect Dis 2005;40(11):1625-1634.

115. Barbut F, Menuet D, Verachten M, Girou E. Comparison of the efficacy of a hydrogen peroxide dry-mist disinfection system and sodium hypochlorite solution for eradication of Clostridium difficile spores. Infect Control Hosp Epidemiol 2009; 30(6):507-514.

116. Wong SK, Kneebone A, Morgan M, Henderson CJ, Morgan A, Jalaludin B. Surgical management of colorectal cancer in south-western Sydney 1997-2001: a prospective series of 1293 unselected cases from six public hospitals. ANZ J Surg 2005; 75(9):776-782.

117. McKibben L, Horan TC, Tokars JI, et al. Guidance on public reporting of healthcare-associated infections: recommendations of the Healthcare Infection Control Practices Advisory Committee. Infect Control Hosp Epidemiol 2005;26(6):580-587.

118. Berenholtz SM, Pham JC, Thompson DA, et al. Collaborative cohort study of an intervention to reduce ventilator-associated pneumonia in the intensive care unit. Infect Control Hosp Epidemiol 2011;32(4):305-314.

119. Farley JE, Doughman D, Jeeva R, Jeffries P, Stanley JM. Department of Health and Human Services releases new immersive simulation experience to improve infection control knowledge and practices among health care workers and students. Am J Infect Control 2012;40(3):258-259.

120. Landers T, Abusalem S, Coty MB, Bingham J. Patient-centered hand hygiene: the next step in infection prevention. Am J Infect Control 2012;40(4 suppl 1):S11-S17.

121. Dubberke ER. Prevention of healthcare-associated Clostridium difficile infection: what works? Infect Control Hosp Epidemiol 2010;31(suppl 1):\$38-\$41.

122. Guyatt $\mathrm{GH}$, Oxman $\mathrm{AD}$, Vist $\mathrm{GE}$, et al. GRADE: an emerging consensus on rating quality of evidence and strength of recommendations. BMJ 2008;336(7650):924-926.

123. GRADE. Canadian Task Force on Preventive Health Care website. http://canadiantaskforce.ca/methods/grade/. Accessed December 31, 2013. 